\title{
Post-partum lower limb neuropathies-intrinsic obstetrical palsies
}

\author{
Dr. Nadeem Zaidi FCPS, FCARCSI, Consultant Anaesthetist, Furness General Hospital \\ Dr. M. Salimuzzaman Bhuiyan FFARCSI, AFFICM, Consultant Anaesthetist, Furness \\ General Hospital
}

\section{INTRODUCTION}

Pregnancy can be associated with various neuropathies. These are generally in the form of mononeuropathies, plexopathy, radiculopathy and polyneuropathies. The most common peripheral neuropathies associated with the pregnancy and post-partum period are Bell's palsy, carpal tunnel syndrome and lower limb neuropathies. Pathophysiology of most of them is related to the pregnancy and hormonal changes associated with it. ${ }^{1}$

The majority of the lower limb peripheral neuropathies of pregnancy are noticed in post-partum period. These are often termed as intrinsic obstetrical palsies related to child birth. A small number of them are related to the anaesthetic techniques used for labour analgesia and to facilitate the process of delivery.

Anaesthetists are often called in to review these patients in the post-partum period. We believe that awareness about this subject would help anaesthetists, midwives and physiotherapists to identify and manage them properly.

In this review we will discuss the aetiology, pathophysiology, clinical presentation and management including the prevention of post-partum palsies.

\section{PATHOPHYSIOLOGY}

Although the incidence of post-partum obstetrical palsies is very low, its impact on the puerperal recovery could be quite significant.

The incidence of post-partum neuropathies involving the lower limb is about $1 \%$ of all deliveries. ${ }^{2}$ Wong and his colleagues ${ }^{3}$ prospectively followed more than 6000 deliveries. They found that lateral cutaneous nerve of thigh and femoral nerve were the common neuropathies in the post-partum period. Signs and symptoms of these neuropathies are variable; a mild sensory impairment to a gross motor deficit.

Neuropathy generally occurs from the mechanical trauma e.g. needle, catheter or intra-neuronal injection of local anaesthetic; presence of neurotoxin and compromised blood flow. Mechanical trauma causes stretch, compression and transaction of nerve fibres resulting in a sensory or motor deficit. During labour peripheral nerves of lower limb are likely to be compressed or stretched due to prolonged lithotomic position or compression by foetal head during prolonged second stage of labour and instrumental delivery. Various risk factors associated with development of lower limb neuropathies are mentioned in Table 1., 5

\section{CLINICAL PRESENTATION}

The main nerve supply of the lower limb is from lumber and lumbosacral plexuses, femoral, obturator and lateral cutaneous nerve of thigh originates from lumber plexus, while sciatic nerve which is the main peripheral nerve of the lower limb is from lumbosacral plexus. The sciatic nerve subsequently divides into tibial and common peroneal nerve.

Neuronal damage during labour occurs either at spinal nerve, nerve root, truncal or peripheral nerve level. It may happen with a spontaneous intervertebral disc herniation, haematoma or thrombosis and presents with a complex set of signs and symptoms. ${ }^{6}$ The patient will need an urgent MRI scan of lumbosacral spine and may need urgent surgical intervention.

Lateral cutaneous nerve of thigh ( $\mathrm{LCN}$ ) and femoral nerve $(\mathrm{FN})$ are most vulnerable to compression injuries at inguinal ligament level resulting from prolonged hip flexion, increase abdominal pressure (retroperitoneal

Risk factors for developing lower limb obstetrical palsies

- Maternal factors

- primigravida

- short maternal height

- cephalo pelvic disproportion

- maternal systemic diseases

- diabetes mellitus

- hypertension

- hypothyroidism

- smoking

- platypelloid pelvis

- increase lumber lordosis

- Foetal factors

- foetal mal presentation (occipito posterior)

- cephalo pelvic disproportion

- $\quad$ Prolonged 2nd stage of labour

- Instrumental delivery

- A wide Pfannensteil incision for caesarean/ section

- Positioning during delivery:

- lithotomy position with prolonged hip flexion and thighs abduction

- prolonged external mechanical compression at knee joint

- knee hyperflexion

- prolonged squatting 
haemorrhage, intra pelvic pathology) and increased lumber lordosis. LCN is also vulnerable to damage with a wide Pfannensteil incision made for caesarean section and use of self-retaining retractors during low abdominal and gynaecological surgery ${ }^{7}$. Femoral nerve neuropathy is presented with a mixture of sensory and motor deficits. There is loss of patellar reflex, weakness of hip flexion and knee extension. Patient has difficulty in climbing upstairs and assuming a standing posture from sitting position (quadriceps weakness). There is also some sensory deficit along the medial side of thigh and calf. ${ }^{8}$

Lithotomy position with thigh abducted and externally rotated makes obturator nerve prone to injury. Clinical presentation includes weakness of thigh adductors and sensory deficit and pain along the upper medial aspect of high. In about $25 \%$ of patients bilateral femoral and obturator nerve involvement has been reported..$^{7,9}$

Lumbosacral plexus is compressed by the foetal head as it passes the posterior pelvic brim. This risk is increased with foetal malpositioning, prolonged second stage of labour and cephalopelvic disproportion. The patient may complain of low back pain, sensory deficit along posterior and lateral aspect of thigh and difficulty of dorsiflexion and eversion of foot. ${ }^{7,10}$

The common peroneal nerve is susceptible to injury due to its superficial location at the level of fibular head and prolonged period of knee flexion or inappropriate placement of legs in stirrups during lithotomy position. Sensory deficit involves lateral aspect of lower leg and dorsum of foot. Patient may also complain of change in their gait with partial or complete foot drop. ${ }^{11}$ The pudendal nerve can be injured at the level of ischial spine during forceps delivery. Urinary retention, bowel dysfunction in the post-partum period with some perineal sensory loss indicates pudendal nerve injury.?

\section{MANAGEMENT}

Management depends on the history of labour and neurological examination. Details of the delivery process e.g. length of the 2 nd stage, position of patient during labour, presence of perineal lacerations, haematoma and use of forceps, are very important to establish any clinical diagnosis.

In majority of cases the neuropathies resolve over a period of 6-8 weeks. ${ }^{7}$ The partial and complete recovery depends on the severity of the injury.

Non-steroidal anti-inflammatory drugs (NSAIDs) and medications for neuropathic pain are useful as the first line of management. Application of a lignocaine patch over the painful area and peripheral nerve blocks are also helpful for symptomatic relief. ${ }^{12}$ Ankle and knee braces are useful to stabilise patient's posture and gait, and pelvic floor exercises and physiotherapy are also useful.

Progression of neurological signs and symptoms, persistent back pain, bladder and bowel dysfunction need further investigation e.g. MRI scan of lower back, urodynamic study, nerve conduction study and input from neurologist.

\section{CONCLUSION}

Postpartum lower limb neuropathies are rare but could have a significant effect on mother's birth experience and subsequent recovery. They may occur with or without anaesthetic intervention. All health care professionals involved in the patient care need to be aware of this subject.

More emphasis should be given on the prevention of this complication. Maternal position during labour should be regularly assessed. Lower limb position should be changed frequently during labour. Prolonged periods of hip flexion, abduction and external rotation should be avoided. Maternal active pushing phase should not be prolonged.

Post-natal follow up is also very important to pick up the pathology early for prompt management. Any suspected case of lower limb neuropathy should be cared and followed up by a team of specialists e.g. neurologist, radiologist, physiotherapist and chronic pain specialist.

\section{REFERENCES}

1. Klein A. Peripheral nerve disease in pregnancy. Clin Obstet Gynecol 2013;56(2):382-88.

2. Boyce H, Plaat, F. Postnatal neurological problems. Continuing Education in Anaesthesia, Critical Care \& Pain 2013;13(2):63-66.

3. Wong CA, Scavone BM, Dugan S, Smith JC, Prather $\mathrm{H}$, Ganchiff JN. et al. Incidence of postpartum lumbosacral spine and lower extremity nerve injuries. Obstet Gynecol 2003;101(2):279-88.

4. Hakeem R, Neppe C. Intrinsic obstetric palsy: case report and literature review. J Clin Diagn Res 2016;10(4): QD 06-7.

5. Sahai-Srivastava S, Amezcua L. Compressive neuropathies complicating normal childbirth: case report and literature review. Birth 2007;34(2):173-75.

6. Kelly ME, Beavis RC, Hattingh S. Spontaneous spinal epidural hematoma during pregnancy. Can J Neurol Sci 2005;32:361-65.

7. O'Neal MA, Chang, LY, Salajegheh, MK. Postpartum spinal cord, root, plexus and peripheral nerve injuries involving the lower extremities: a practical approach. Anesthesia \& Analgesia 2015;120(1):141-48.

8. Peirce C, O'Brien, C O'Herlihy C. Postpartum femoral neuropathy following spontaneous vaginal delivery. J Obstet Gynaecol 2010;30(2):203-4.

9. Nogajski JH, Shnier RC, Zagami AS. Post-partum obturator neuropathy. Neurology 2004;63(12):245051 .

10. Dastkhosh A, Razavi M, Gilani MT. Foot drop after spinal anesthesia for cesarean section: a case report. Local Reg Anesth 2018;11:45-47.

11. Radawski MM, Strakowski JA, Johnson EW. Acute common peroneal neuropathy due to hand positioning in normal labour and delivery. Obstetrics and Gynecology 2011;18(2):421-23.

12. Butchart AG, Mathews M, Surendran A. Complex regional pain syndrome following protracted labour. Anaesthesia 2012;67:1272-74.

Correspondence to: syed-nadeem.zaidi@mbht.nhs 